\title{
Novel homobarringtonie-containing therapy for the treatment of patients with primary acute myeloid leukemia that are resistant to conventional therapy
}

\author{
JINGSONG HE ${ }^{1,2}$, LI LI ${ }^{1}$, JINGJING ZHU ${ }^{1}$, WEIYAN ZHENG ${ }^{1,2}$, \\ WENJUN WU ${ }^{1,2}$, YANLONG ZHENG ${ }^{1}$ and XIUJIN YE $^{1}$ \\ ${ }^{1}$ Department of Hematology; ${ }^{2}$ Bone Marrow Transplant Center, The First Affiliated Hospital, \\ School of Medicine Zhejiang University, Hangzhou, Zhejiang 310003, P.R. China
}

Received September 26, 2016; Accepted January 12, 2017

DOI: $10.3892 / 01.2017 .7084$

\begin{abstract}
The current study investigated the efficacy and safety of a novel treatment regime consisting of homobarringtonie, cytosine arabinoside and etoposide (HCE) for the treatment of primary acute myeloid leukemia (AML). In the present study, 141 patients diagnosed with AML were divided into the HCE $(n=47)$ and the conventional AML therapy, consisting of idamycin combined with cytarabine (IA; $n=94$ ), treatment groups. The measured patient outcome parameters were the emission and response rates, as well as medication-induced adverse events, with a median follow-up time of 28 months. There was no significant difference in the 3-year relapse-free survival rate between the HCE and IA treatment groups. The occurrence and severity of hematological or non-hematological toxicity did not differ between the two groups. However, of the 26 patients that demonstrated a poor response to the IA treatment, 19 cases were administered the HCE treatment and 14 of these patients achieved complete remission (CR). Of the 10 patients that demonstrated a poor response to the HCE treatment, 8 patients were administered the IA treatment and 7 of these achieved CR. Therefore, HCE may be an effective treatment regimen for patients with primary AML. As there was no cross-resistance between the HCE and IA regimens, HCE may be an alternative option for patients that respond poorly to IA induction therapy.
\end{abstract}

Correspondence to: Dr Xiujin Ye, Department of Hematology, The First Affiliated Hospital, School of Medicine Zhejiang University, 79 Qingchun Road, Hangzhou, Zhejiang 310003, P.R. China

E-mail: yxjsunny@zju.edu.cn

Abbreviations: AML, acute myeloid leukemia; DNR, daunorubicin; IDA, idarubicin; RFS, relapse free survival; OS, overall survival; HBT, homobarringtonie; CML, chronic myeloid leukemia; FAB, French-American-British; ANC, absolute neutrophil count; CR, complete remission; $\mathrm{PR}$, partial remission

Key words: acute myeloid leukemia, cytarabine, etoposide, homobarringtonie, idamycin

\section{Introduction}

Acute myeloid leukemia (AML) is a group of heterogeneous malignant blood tumors, and is the most common variant of adult acute leukemia, which typically causes hematopoietic failure as a result of bone marrow infiltration (1). Daunorubicin and idarubicin (IDA) anthracycline drugs combined with cytosine arabinocide (Ara-c) in the ' $7+3$ ' regimen is the established inductive chemotherapy for AML (2-4).

Previous clinical studies have focused on improving the inductive regimen for patients with AML, including increasing the dosage of Ara-c from $100-200 \mathrm{mg} / \mathrm{m}^{2}$ to higher doses $(5,6)$, increasing the dosage of daunorubicin (from 45 to $90 \mathrm{mg} / \mathrm{m}^{2}$ ) or replacing daunorubicin with idarubicin, which may be effective for younger patients and patients with a good prognosis (7-9). A third drug may be added to the original ' $7+3$ ' regimen, such as fludarabine, cladribine or etoposide, to improve the remission rate, the relapse free survival (RFS) rate and the overall survival (OS) rate following induction therapy $(10,11)$.

Homobarringtonie (HBT; also known as homoharringtonine) is a natural plant alkaloid extracted from the endemic Chinese plant Cephalotaxus harringtonia, and is reported to promote cell death in a number of tumor types, depolymerize cell ribosomes and inhibit protein synthesis $(12,13)$. HBT also prevents DNA synthesis and targets the G1/G2 phases of the cell cycle $(14,15)$. Following the demonstration of the therapeutic efficacy of omacetaxine mepesuccinate (a type of synthetic HBT) for chronic myeloid leukemia (CML) $(16,17)$, the United States Food and Drug Administration approved its use as a tyrosine kinase inhibitor for the treatment of resistant chronic phase or accelerated CML (18). Previous Chinese studies have added HBT as the third drug to the conventional inductive therapy for AML (19-22), and these studies demonstrated that the treatment of HBT combined with aclarubicin and Ara-c resulted in a complete remission (CR) rate of $83 \%$. As a result, an HBT, Ara-c and aclarubicin-containing chemotherapy regimen has been recommended for the treatment of AML (19-22). However, there have been little studies focusing on the efficacy and safety of HBT treatment combined with Ara-c and etoposide as a first line therapy for AML. Therefore, the present study 
evaluated the efficacy and safety of combined HBT, Ara-c and etoposide (HCE) as an induction therapy in Chinese patients with AML aged $<65$ years. The present cohort study compares this novel treatment regimen with the conventional idamycin combined with Ara-c ' $7+3$ ' treatment (IA) regimen.

\section{Patients and methods}

Patients. Between March 2011 and April 2014, 141 patients diagnosed with AML aged 18-65 years were admitted to the Hematology Department of The First Affiliated Hospital of Medical College of Zhejiang University (Hangzhou, China). According to the bone marrow examination, cell morphology, cell immune phenotypic, cytogenetic and molecular biology examination and using the World Health Organization blood system malignant tumor diagnostic criteria from 2008 (23), all patients were diagnosed with AML and acute promyelocytic myelogenous leukemia (M3) was excluded. Patients had no dysfunction of the major organs including the heart, liver and kidney. The follow-up time ended in February 2015. The current study was certified by The First Affiliated Hospital of Medical College of Zhejiang University Clinical Research Ethics Committee. Written consent was obtained from all patients and the privacy rights of patients were maintained. Using risk stratification based on bone marrow leukemic cell genetic analysis and the molecular abnormalities guidelines from the National Comprehensive Cancer Network (2), the patients were separated into three diagnostic criteria: high risk, intermediate risk and low risk. Patients with a good prognosis were defined as having recurring cytogenetic abnormalities including inv(16) or $\mathrm{t}(16 ; 16), \mathrm{t}(8 ; 21), \mathrm{t}(15 ; 17)$; a normal karyotype with nucleophosmin mutation and no Fms-like tyrosine kinase 3 (FLT-3)-internal tandem duplication (ITD) mutations, or isolated CCAAT/enhancer-binding protein $\alpha$ double mutants. The patients with a poor prognosis were defined as having complicated karyotypes ( $\geq 3$ types of abnormal chromosome), a single chromosome karyotype of $-5,5 \mathrm{q}-,-7,7 \mathrm{q}-$, 11q12[no $\mathrm{t}(9 ; 11)], \operatorname{inv}(3), \mathrm{t}(3 ; 3), \mathrm{t}(6 ; 9), \mathrm{t}(9 ; 22)$ and molecular abnormalities with a normal karyotype and FLT3-ITD mutation. Patients with a moderate prognosis were defined as having a normal karyotype, or separate +8 , or $\mathrm{t}(9 ; 11)$, or other unmentioned cytogenetic abnormalities, as well as molecular abnormalities with inv (16), $\mathrm{t}(16 ; 16), \mathrm{t}(8 ; 21)$ and c-KIT mutation (2). Routine interphase chromosome $\mathrm{R}$ banding techniques were performed for cytogenetic evaluation (24) and DNA polymerase chain reaction was used to identify molecular abnormalities (25). The French-American-British (FAB) classification system was used according to the proposals of the FAB co-operative group (26).

Treatments. The composition of the HCE treatment scheme was as follows: HBT (Hangzhou Minsheng Pharmaceutical Industry Group Company Ltd., Hangzhou, China) was administered at $4 \mathrm{mg} / \mathrm{day}$ on days 1-7 and was divided into 2 intravenous infusions for 3-4 h each; a dose of $100 \mathrm{mg} / \mathrm{m}^{2}$ Ara-c (Pfizer Inc., Shanghai, China) was administered as a continuous intravenous injection on days 1-7; a dose of $70 \mathrm{mg} / \mathrm{m}^{2}$ VP16 (also known as etoposide; Qilu Pharmaceutical Co. Ltd., Jinan, China) was administered on days 1-5 or 1-7 via intravenous infusion for 2-3 h. The composition of the IA regimen was $7-9 \mathrm{mg} / \mathrm{m}^{2}$ Idamycin (idarubicin; Pfizer, Inc.) by intravenous infusion on days $1-3$ and $100 \mathrm{mg} / \mathrm{m}^{2}$ Ara-c administered by continuous intravenous injection on days 1-7. All patients completed one of the described induction therapies. The choice of induction therapy did not follow the randomized principle. The patients were admitted into the groups with the 1:2 (HCE:IA) ratio, based on the decision of the oncologist and patients and their family's preference on treatment (including financial status) were considered. The toxicity of the therapy was evaluated according to the National Cancer Institute common toxicity criteria (27). Following induction therapy or after 3-4 weeks, peripheral blood cells were obtained, including white blood cells, and a bone marrow biopsy was performed. When patients achieved complete remission (CR), consolidation therapy was administered. Patients that achieved partial remission (PR) were treated with a further course of induction therapy. Patients with peripheral blood neutrophils that were $<0.5 \times 10^{9} / 1$ received $300-450 \mu \mathrm{g} /$ day colony stimulating factor until the peripheral white blood cell count was $\geq 2.0 \times 10^{9} / 1$ or neutrophils were $\geq 1.0 \times 10^{9} / 1$ (normal range, $\left.2.5-7.5 \times 10^{9} / 1\right)$. Antibiotics, antifungal drugs and blood infusion products were administered according to the clinical treatment guidelines as supportive treatment (2).

Patients that did not achieve PR following one course or CR following two courses were administered an alternative treatment scheme (patients that did not respond to the HCE scheme were administered the IA scheme and patients that did not respond to the IA scheme were administered the HCE scheme) and this was administered following the induction therapy regimen after the patient was evaluated.

Post-remission therapy. Patients that achieved CR received further consolidation therapy, which included one course of HCE or IA treatment followed by a moderate dose of $2 \mathrm{~g} / \mathrm{m}^{2}$ Ara-c over $12 \mathrm{~h}$ on days 1,3 and $5,7-9 \mathrm{mg} / \mathrm{m}^{2}$ IDA on days $1-3$ and $70 \mathrm{mg} / \mathrm{m}^{2}$ VP16 on days $1-5$ for $2-3$ courses. Patients that were considered to have intermediate or high risk were treated with maintenance therapy, which included the aclacinomycin/Ara-c/etoposide regimen (20 mg aclacinomycin by intravenous infusion for 3-4 $\mathrm{h}$ on days $1-5 ; 100 \mathrm{mg} / \mathrm{m}^{2}$ Ara-c by continuous intravenous injection on days $1-5 ; 70 \mathrm{mg} / \mathrm{m}^{2}$ VP16 on days $1-5$ by intravenous infusion for $2-3 \mathrm{~h}$ ) and the HBT/Ara-c regimen (4 mg/day HBT on days $1-5$ divided into two intravenous infusions each for $3-4 \mathrm{~h} ; 100 \mathrm{mg} / \mathrm{m}^{2}$ Ara-c in a continuous intravenous injection on days 1-5) respectively, for three courses. Certain patients were treated with an autologous stem cell or an allogeneic hematopoietic stem cell transplant (Table I) during their enrollment in the present study.

Outcome parameters. The outcome parameters that were evaluated were the CR rate following one course of treatment, the three-year OS rate, the RFS rate, the duration of time a patient in CR demonstrated absolute neutrophil count (ANC) reduction (measured from the beginning of chemotherapy to the final day of a patient having an ANC of $<0.5 \times 10^{9} / 1$; normal range, 2.5-7.5x $10^{9} / 1$ ), the minimum value of ANC during the inhibition period and the duration of time required to reach this minimum ANC value. Early mortality was considered to have occurred between the beginning of chemotherapy and 30 days after the beginning of chemotherapy. OS was determined 
Table I. Characteristics of patients.

\begin{tabular}{|c|c|c|c|}
\hline Characteristics & $\operatorname{HCE}(\%) \mathrm{n}=47$ & $\mathrm{IA}(\%) \mathrm{n}=94$ & P-value \\
\hline \multicolumn{4}{|l|}{ Sex } \\
\hline Male & $25(53.2)$ & $44(46.8)$ & \multirow[t]{2}{*}{0.475} \\
\hline Female & $22(46.8)$ & $50(53.2)$ & \\
\hline \multicolumn{4}{|l|}{ Age, years } \\
\hline Median & 42 & 43 & \multirow[t]{2}{*}{0.922} \\
\hline Range & $19-64$ & $18-65$ & \\
\hline \multicolumn{4}{|c|}{ FAB classification } \\
\hline M0 & $4(8.5)$ & $5(5.3)$ & \multirow[t]{6}{*}{$0.012^{\mathrm{a}}$} \\
\hline M1 & $3(6.4)$ & $7(7.4)$ & \\
\hline M2 & $15(31.9)$ & $46(48.9)$ & \\
\hline M4 & $7(14.9)$ & $1(1.1)$ & \\
\hline M5 & $18(38.3)$ & $33(35.1)$ & \\
\hline M6 & 0 & $2(2.1)$ & \\
\hline \multicolumn{4}{|c|}{ WBC count at diagnosis } \\
\hline$\geq 100 \times 10^{9} / 1$ & $6(12.8)$ & $9(9.6)$ & \multirow[t]{3}{*}{0.624} \\
\hline $50-100 \times 10^{9} / 1$ & $5(10.6)$ & $15(16.0)$ & \\
\hline$<50 \times 10^{9} / 1$ & $36(76.6)$ & $70(74.4)$ & \\
\hline \multicolumn{4}{|c|}{ Cytogenetic risk group } \\
\hline Favorable & $13(27.6)$ & $24(25.5)$ & \multirow[t]{3}{*}{0.649} \\
\hline Intermediate & $24(51.1)$ & $55(58.5)$ & \\
\hline Unfavorable & $10(21.3)$ & $15(16.0)$ & \\
\hline \multicolumn{4}{|l|}{ Transplantation } \\
\hline Auto & $1(2.1)$ & $3(3.2)$ & \multirow[t]{2}{*}{0.277} \\
\hline Allo & $3(6.4)$ & $14(14.9)$ & \\
\hline
\end{tabular}

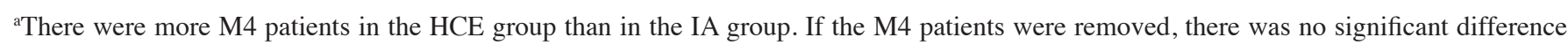
between the two groups $(\mathrm{P}=0.433)$. HCE, homobarringtonie, cytosine arabinoside and etoposide; IA, idamycin and cytosine arabinocide; $\mathrm{n}$, number of patients; FAB, French-American-British; WBC, white blood cell count.

from the beginning of treatment to the date of mortality or final follow-up. The duration of RFS was the length of time between achieving $\mathrm{CR}$ and recurrence, mortality or the final follow-up. Patient follow-up was performed via outpatient and inpatient medical records and by telephone communications.

Efficacy evaluation criteria. The definition of CR was: Peripheral blood cell recovery, including neutrophil counts of $\geq 1.5 \times 10^{9} / 1$ (normal range, $2.5-7.5 \times 10^{9} / 1$ ), platelets of $\geq 100 \times 10^{9} / 1$ (normal range, 100-300x10 $/ 1$ ), hemoglobin of $\geq 100 \mathrm{~g} / 1$ (normal range, 120-160 g/l) with no leukemia cells; bone marrow leukemia cells of $<5 \%$; no extramedullary invasion and mild splenic enlargement. If bone marrow leukemia cells were $<5 \%$ with no extramedullary invasion, but the peripheral blood cells did not achieve complete recovery, the condition was referred to as $\mathrm{CR}$ with incomplete blood count recovery (CRi). The definition of PR was as follows: Neutrophil count of $\geq 1.5 \times 10^{9} / 1$; platelet count of $\geq 50 \times 10^{9} / 1$; no leukemia cells; bone marrow leukemia cells of 5-20\%; no extramedullary invasion or enlarged lymph nodes with a diameter of $<2 \mathrm{~cm}$; subcostal spleen of $<2 \mathrm{~cm}$; subcostal liver of $<5 \mathrm{~cm}$; significantly improved clinical symptoms. Ineffective treatment was determined to have occurred if a patient did not achieve the
CR or PR conditions. Early mortality was defined as mortality following induction therapy and prior to efficacy evaluation.

All patients received full clinical evaluations prior to induction therapy, subsequent consolidation therapy and maintenance therapy. The clinical evaluations included peripheral blood cell counts and classification, liver and kidney function tests, an electrocardiogram and a cardiac ultrasound examination. Additionally, bone marrow aspiration smear was performed 3-4 weeks following each course of treatment to evaluate the efficacy of the treatments.

Statistical analysis. SPSS version 18.0 (SPSS, Inc., Chicago, IL, USA) was used for all statistical analyses. A Pearson, $\chi^{2}$ or Fisher's exact tests were used to compare the frequency distributions between groups. An independent sample t-test was used to compare the mean between two groups and the Kaplan-Meier was used to analyze the RFS and OS of patients. $\mathrm{P}<0.05$ was considered to indicate a statistically significant difference.

\section{Results}

Characteristics of the patients with AML. There was a total of 141 patients with a median age of 42 years, including 
Table II. Induction therapy efficacy.

\begin{tabular}{|c|c|c|c|}
\hline Characteristics & $\operatorname{HCE}(\%) \mathrm{n}=47$ & $\mathrm{IA}(\%) \mathrm{n}=94$ & P-value \\
\hline \multicolumn{4}{|l|}{ Complete remission $^{\mathrm{a}}$} \\
\hline Total & $37(78.7)$ & $68(72.3)$ & 0.413 \\
\hline 1st cycle CR & $31(66.0)$ & $56(59.6)$ & 0.462 \\
\hline 2nd cycle CR & $6(12.8)$ & $12(12.8)$ & \\
\hline No remission & $8(17.0)$ & $21(22.3)$ & \\
\hline No evaluation & $2(4.3)$ & $5(5.3)$ & \\
\hline Early mortality & $1(2.1)$ & $5(5.3)$ & 0.664 \\
\hline $\begin{array}{l}\text { Patients assigned to } \\
\text { the alternative regimen }{ }^{\mathrm{b}}, \mathrm{n}\end{array}$ & 8 & 19 & \\
\hline $\mathrm{CR}$ & $7(87.5)$ & $14(73.7)$ & 0.633 \\
\hline Total CR rates, $\mathrm{n}$ & $51(77.3)$ & $75(73.5)$ & 0.584 \\
\hline
\end{tabular}

${ }^{a}$ Includes patients with complete bone marrow remission with incomplete recovery of blood count. ${ }^{b}$ Patients that did not respond to treatment. HCE, homobarringtonie, cytosine arabinoside and etoposide; IA, idamycin and cytosine arabinocide; $n$, number of patients; CR, complete remission.

69 males and 72 females. All patients underwent cytogenetic examination and there were $37(26.3 \%)$ patients with a good prognosis (low risk group), 79 patients $(56.0 \%)$ with a moderate prognosis (intermediate risk group) and 25 (17.7\%) patients with a poor prognosis (high risk group). In total, 47 patients were administered HCE treatment and 94 patients received IA induction therapy; the patients and the disease characteristics of the two groups are presented in Table I. Following statistical analysis, there was a significantly higher number of patients with the M4 subgroup FAB classification in the HCE treatment group compared with the number of $\mathrm{M} 4$ patients in the IA treatment groups (14.9 vs. $1.1 \%$; $\mathrm{P}=0.012$ ). There were no other significant differences between patients and disease characteristics, including age, sex, peripheral white blood cell count at initial diagnosis, risk stratification based on cytogenetic and molecular biology examination and treatment with autologous or allogeneic hematopoietic stem cell transplants.

Induction therapy efficacy. In the current study, a total of 141 patients with primary AML received 1 or 2 consecutive courses of treatment. Of these, 105 cases $(74.5 \%)$ achieved $\mathrm{CR}$ or $\mathrm{CRi}$ and 87 of these cases $(61.7 \%)$ obtained remission following the first chemotherapy cycle. The overall remission rate following 1 course of treatment was comparable between the HCE and IA groups (78.7 vs. $72.3 \%$ and 66.0 vs. $59.6 \%$, respectively). A total of 7 patients did not receive therapeutic efficacy evaluation, 6 of these cases $(4.3 \%)$ were as a result of early mortality (within 30 days following the start of induction therapy). A single patient (2.1\%) in the HCE group succumbed to central nervous system bleeding. There were 5 cases of early mortality (5.3\%) in the IA group, of which 4 were the result of central nervous system bleeding and 1 was from septic shock. There was no significant difference in the number of early mortality between the two groups. A total of 10 patients responded poorly to HCE treatment, of which 2 cases transferred to other hospitals and the remaining 8 patients were administered the IA scheme and subsequently,
7 of these patients achieved CR. Among the 21 patients that responded poorly to IA treatment, 19 were administered the HCE regimen and 14 achieved CR (Table II).

The therapeutic effects of the treatment subgroups (HCE or IA regimen) were analyzed separately. Comparing the HCE and the IA group following induction therapy, there were no significant differences in the $\mathrm{CR}$ rate of patients between the sexs or age groups ( $<50$ or $>50$ years).

With regard to the FAB classification, the $\mathrm{CR}$ rate of the M4 and M5 subgroup of patients (FAB2) was significantly increased in the HCE group ( 84 vs. $58.8 \% ; \mathrm{P}=0.038$ ).

In the IA group, the therapeutic efficacy of induction therapy in the FAB2 (M4 and M5) subgroup was reduced compared with the FAB1 (M0, M1, M2 and M3 subgroups) group (58.8 vs. $80.0 \%$; $\mathrm{P}=0.027)$.

The treatment efficacy for IA patients between the risk groups was significantly different $(\mathrm{P}=0.003)$, the $\mathrm{CR}$ was 95.8, 65.5 and $60.0 \%$ in the low, intermediate and high risk patients, respectively. In addition, the CR rates of the HCE and IA groups were not associated with the results of the peripheral white blood cell counts performed at the time of diagnosis (Table III).

Adverse reactions. The primary hematological adverse reactions that were detected include granulocyte deficiency, severe thrombocytopenia and anemia. The median duration of time of granulocyte deficiency (defined as a peripheral blood granulocyte count of $<0.5 \times 10^{9} / 1$ ) in the HCE and IA groups were 17 and 15 days, respectively. The median durations of severe thrombocytopenia (defined as a peripheral blood platelet count of $<20 \times 10^{9} /$ l) were 15 and 17 days, respectively, and there was no significant difference between the two groups. During induction therapy, a number of patients required erythrocyte and platelet suspension infusions and there was no significant difference in the quantity of blood cell suspension infusions that were required between the HCE and IA groups (Table IV).

During the induction therapy process, the primary non-hematological adverse reaction that was identified was 
Table III. Induction therapy efficacies of the subgroups.

\begin{tabular}{|c|c|c|c|c|c|}
\hline \multirow[b]{2}{*}{ Characteristics } & \multicolumn{2}{|c|}{$\operatorname{HCE}(n=47)$} & \multicolumn{2}{|c|}{ IA $(n=94)$} & \multirow[b]{2}{*}{ P-value } \\
\hline & $\mathrm{n}$ & $\mathrm{CR}, \mathrm{n}(\%)$ & $\mathrm{n}$ & $\mathrm{CR}, \mathrm{n}(\%)$ & \\
\hline \multicolumn{6}{|l|}{ Sex } \\
\hline Male & 25 & $20(80.0)$ & 44 & $32(72.7)$ & 0.500 \\
\hline Female & 22 & $17(77.3)$ & 50 & $36(72.0)$ & 0.640 \\
\hline \multicolumn{6}{|l|}{ Age, years } \\
\hline$<50$ & 35 & $26(74.3)$ & 65 & $49(75.4)$ & 0.904 \\
\hline$\geq 50$ & 12 & $11(91.7)$ & 29 & $19(65.5)$ & 0.128 \\
\hline \multicolumn{6}{|l|}{ FAB classification } \\
\hline $\mathrm{FAB}^{\mathrm{a}}$ & 22 & $16(72.7)$ & 60 & $48(80.0)$ & 0.551 \\
\hline $\mathrm{FAB}^{\mathrm{b}}$ & 25 & $21(84.0)$ & 34 & $20(58.8)$ & 0.038 \\
\hline \multicolumn{6}{|l|}{$\mathrm{WBC}$ at diagnosis } \\
\hline$<50 \times 109 / 1$ & 36 & $28(77.8)$ & 70 & $53(75.7)$ & 0.813 \\
\hline$\geq 50 \times 109 / 1$ & 11 & $9(81.8)$ & 24 & $15(62.5)$ & 0.435 \\
\hline \multicolumn{6}{|l|}{ Risk stratification } \\
\hline Low risk & 13 & $11(84.6)$ & 24 & $23(95.8)$ & 0.278 \\
\hline Intermediate risk & 24 & $18(75.0)$ & 55 & $36(65.5)$ & 0.402 \\
\hline High risk & 10 & $8(80.0)$ & 15 & $9(60.0)$ & 0.402 \\
\hline
\end{tabular}

${ }^{\mathrm{a}} \mathrm{FAB} 1$ refers to FAB classification as M0, M1, M2, M6 patients. ${ }^{\mathrm{b}} \mathrm{FAB} 2$ refers to FAB classification as M4 and M5 patients. HCE, homobarringtonie, cytosine arabinoside and etoposide; IA, idamycin and cytosine arabinocide; n, number of patients; CR, complete remission; FAB, French-American-British; WBC, white blood cell count.

Table IV. Treatment of adverse reactions and blood cell infusion.

\begin{tabular}{lcc}
\hline Adverse reactions & HCE $(\mathrm{n}=47)$ & IA (n=94) \\
\hline Granulocytopenia phase, days (range) & $17(3->30)$ & $15(7->30)$ \\
Platelet deficiency phase, days (range) & $15(7->30)$ & $17(1->30)$ \\
Red blood cell suspension & & 0.184 \\
Infusion, units (range) & $6(0-16)$ & $5(0-14.5)$ \\
Platelet suspension infusion, units (range) & $25(10-95)$ & $30.5(0-86)$ \\
Level $\geq 3$ infection, $n(\%)$ & $18(38.3)$ & $45(47.8)$
\end{tabular}

HCE, homobarringtonie, cytosine arabinoside and etoposide; IA, idamycin and cytosine arabinocide; n, number of patients.

infection. There were 18 cases $(38.3 \%)$ of level 3-4 infections (27) in the HCE group and 41 cases (47.8\%) in the IA group, but there was no significant difference between these results. Infection occurred at numerous sites and included pulmonary infection, intestinal infection, sepsis, soft tissue infection and fever from unknown causes (1 patient from the IA group succumbed to septic shock). Another level 3-4 non-hematological adverse reaction that was identified was bleeding, and cases included bleeding from the oral cavity, nasal mucosa, digestive tract, urinary tract and vaginal bleeding. A total of 5 of the most severely affected patients succumbed to central nervous system bleeding; 1 of these cases was from the HCE group and 4 cases were from the IA group. During treatment, there were no severe heart, liver, nervous system or other vital organ injuries identified.
Medical expenses of induction therapy. During the treatment periods, all patients were hospitalized and the cost of induction therapy (the cost of the first induction therapy, excluding 6 cases of early mortality) in the HCE group was 58,358.53 Yuan (RMB) and in the IA group was 83,625.28 Yuan (RMB). Therefore, the cost of HCE induction therapy was significantly lower compared with that of the IA group $(t=2.95, \mathrm{P}=0.004)$.

Survival rates of patients. All patients that received 1 or 2 courses of induction therapy and those that achieved complete remission were enrolled onto consolidation therapy and follow-up. The follow-up period ended in February 2015 and the median follow-up time was 28 months. There were 37 cases in the HCE group that achieved CR following 
A

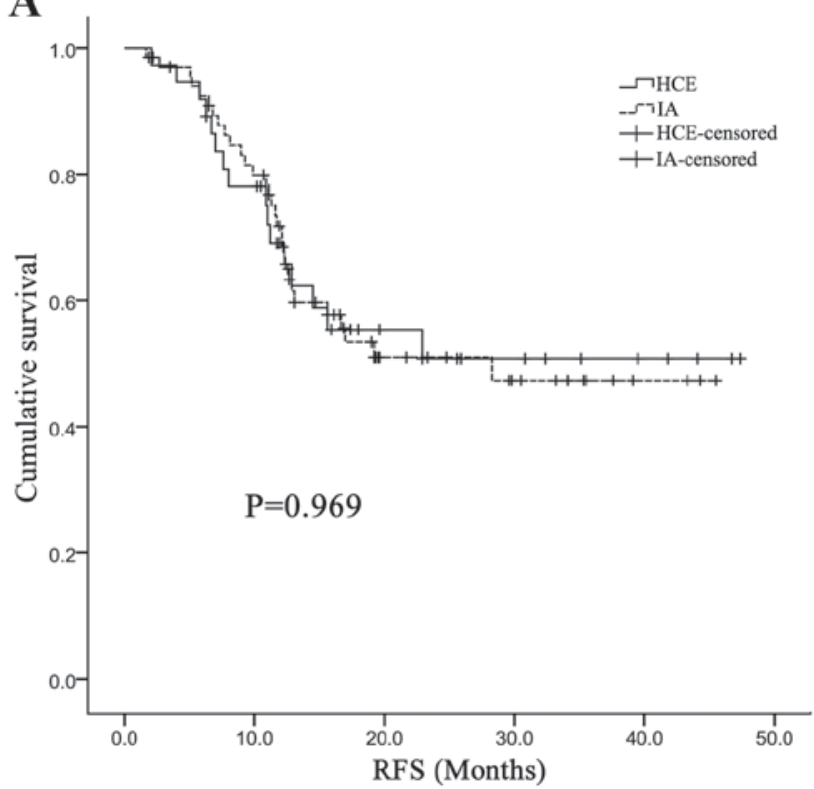

B

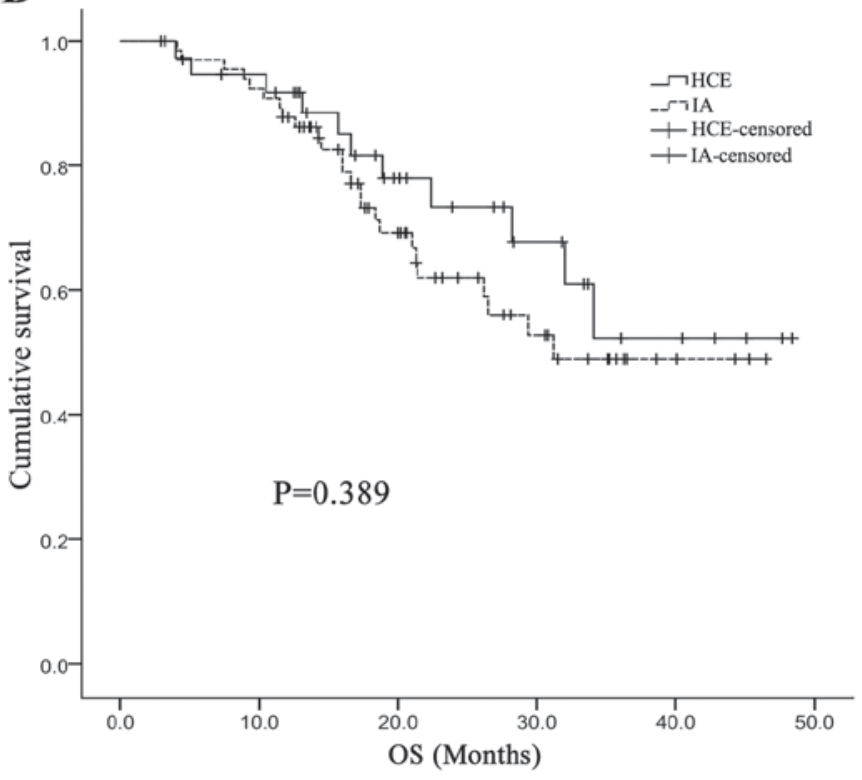

Figure 1. (A) RFS and (B) OS of patients with acute myeloid leukemia in the HCE and IA treatment groups. RFS, relapse-free survival; OS, overall survival; HCE, homobarringtonie, cytosine arabinoside and etoposide; IA, idamycin and cytosine arabinocide.

induction therapy with an overall $50.8 \%$ 3-year RFS, including 2 cases that received allogeneic hematopoietic stem cell transplantation with long-term disease-free survival, 1 case that was lost to follow-up and 16 cases that relapsed during follow-up. There were 68 cases in the IA group that achieved CR following induction therapy with an overall $47.3 \% 3$-year RFS, including 1 case that received autologous transplantation, 11 cases that received allogeneic transplantation (10 cases with long-term disease-free survival, 1 case of mortality due to disease progression), 3 cases in which follow-up was not completed and 30 cases that relapsed during follow-up. There was no significant difference in RFS between the HCE and IA groups ( $\mathrm{P}=0.969$; Fig. 1A).

At the completion of follow-up, there were 47 patients in the HCE group (3-year OS rate was 52.2\%) and of these 11 succumbed to the disease, 9 from disease progression and 2 cases $(4.3 \%)$ from drug toxicity or other causes (1 from sepsis; 1 for indeterminate reasons). There were 25 cases of mortality in the IA group (3-year OS rate was 49.0\%) included 20 cases from disease progression and 5 cases $(5.3 \%, 5 / 94)$ from toxicity (1 case of uncontrollable massive hemoptysis; 2 from intracranial hemorrhage; 1 from sepsis; 1 for other reasons). There was no significant difference in the OS rate between the HCE and IA groups ( $\mathrm{P}=0.389$; Fig. 1B).

According to the FAB classifications, the M4 and M5 subgroup patients (FAB2) had a reduced RFS in the HCE and in the IA group $(\mathrm{P}=0.063$ and $\mathrm{P}=0.013$, respectively; Fig. 2A and B), but the OS was comparable across the FAB M4 and M5 subgroups $(\mathrm{P}=0.112$ and $\mathrm{P}=0.192$, respectively; Fig. 2C and D). The high, intermediate and low risk groups were divided according to cytogenetic and molecular abnormalities. In the IA group, the RFS and OS of the risk groups were significantly different $(\mathrm{P}=0.001, \mathrm{P}=0.011$, respectively; Fig. 3). By contrast, in the HCE group, the RFS and OS were comparable between the risk subgroups $(\mathrm{P}=0.482, \mathrm{P}=0.358$, respectively; Fig. 3). Additionally, in the HCE and IA groups the RFS and OS of patients from various subgroups (including age, FAB classification, white blood cell count at diagnosis and cytogenetic and molecular risk stratification) were not significantly different (Table V).

\section{Discussion}

HBT has been investigated for $>40$ years in Chinese studies (4,28-32). HBT has been used in China to treat acute myeloid leukemia since the 1970s (4,28-32). However, the underlying mechanistic action of HBT against tumor cells remains to be elucidated. Previous studies have indicated that HBT blocks protein synthesis by acting on the ribosomal A site in eukaryotic cells (13), particularly in the G1 and G2 phases of the cell cycle $(14,15)$. In addition, HBT affects the expression of caspase-3 and B-cell lymphoma 2 and its downregulation promotes cell apoptosis, but may also trigger autophagosome activity $(33,34)$. Another previous study demonstrated that HBT upregulated myosin- 9 and this overexpression promoted cell cycle arrest in the $\mathrm{S}$ and $\mathrm{G} 2 / \mathrm{M}$ phases and induced leukemia cell apoptosis (35).

Kantarjian et al (32) performed a meta-analysis of the therapeutic effects of HBT-based regimens for patients with AML. These included 21 clinical trials and 1,310 patients with AML, predominantly from China, published between 2006 and 2013 (32). The results identified that the average $\mathrm{CR}$ rate of the combination treatment of HBT with Ara-c and anthracyclines (daunorubicin, idarubicin, aclacinomycin and mitoxantrone) was $65.2 \%$. However, the majority of these studies were retrospective, non-randomized, small clinical trials (32) and therefore, require validation by randomized controlled clinical trials.

A multicenter, prospective, randomized clinical trial performed by Jin et al (20) identified that the CR rate of 
Table V. Survival rates of patients in each subgroups.

\begin{tabular}{|c|c|c|c|}
\hline \multicolumn{2}{|c|}{$\operatorname{HCE}(n=37)$} & \multicolumn{2}{|c|}{ IA $(n=68)$} \\
\hline $\mathrm{n}$ & 3 -year, \% & $\mathrm{n}$ & 3 -year, \% \\
\hline
\end{tabular}

Relapse-free survival

Age, years

$<50$

$\geq 50$

26

46.7

62.3

49

19

48.1

47.8

0.817

FAB classification

FAB $^{\mathrm{a}}$

16

65.2

39.7

48

20

53.9

27.0

$\mathrm{FAB}^{\mathrm{b}}$

21

28

$<50 \times 10^{9} / 1$

$\geq 50 \times 10^{9} / 1$

9

52.7

53

47.6

45.9

0.86

44.4

15

69.3

41.5

Intermediate risk

High risk

11
18

8

Overall survival

Age, years

$<50$

26

11

FAB classification

$\mathrm{FAB}^{\mathrm{a}}$

16

21

FAB2 $^{\text {b }}$

$\mathrm{WBC}$ at diagnosis

$<50 \times 10^{9} / 1$

$\geq 50 \times 10^{9} / 1$

28

9

Risk stratification

Low risk

High risk
50.9

66.3

80.0

29.6

58.6

41.5

79.5

44.7

29.2
23

36

67.2

46.5

0

0.919

0.736

0.130

55.6

0.556

49

19

27.6

0.566

48.9

0.191

20

47.1

0.619

49.7

0.435

53

15

46.6

0.576

68.1

0.838

23

36

47.8

0.333

0.237

${ }^{\mathrm{a}} \mathrm{FAB} 1$ refers to $\mathrm{FAB}$ classification as M0, M1, M2 and M6 patients. ${ }^{\mathrm{b}} \mathrm{FAB} 2$ refers to FAB classification as M4 and M5 patients. HCE, homobarringtonie, cytosine arabinoside and etoposide; IA, idamycin and cytosine arabinocide; n, number of patients; WBC, white blood cell count; FAB, French-American-British.

HBT/Ara-c/daunorubicin induction therapy was $67 \%$ and the 3-year event free survival (EFS) rate was $32.7 \%$, which was higher compared with the Ara-c/daunorubicin regimen (61 and $23.1 \%$, respectively), but this result was not statistically significantly different. The CR rate of the HBT/Ara-c/aclarubicin regimen was $73 \%$ and had a 3 -year EFS of $35.4 \%$, which was significantly increased compared with that of the Ara-c/daunorubicin regimen (20).

The application of an HCE scheme for myeloid leukemia has not been the focus of many studies and the current study demonstrates that treatment with the HCE scheme (HBT combined with Ara-c and etoposide) produced similar effects compared with the HBT/Ara-c/aclarubicin regime (CR, 78.7\%; 3-year EFS, 50.8\%). The CR rate of the two consecutive HCE treatment courses was 78.7 and $66.0 \%$ for a single treatment course, which is increased in comparison with a CR of 72.3 and $59.6 \%$, following 2 courses or a single course of the IA regimen. The early mortality rate was lower in the HCE treated group compared with the IA treated group, but this difference was not statistically significant. By contrast, younger patients treated with the classical ' $7+3$ ' daunorubicin/Ara-c regime had an overall CR rate of $60-70 \%$. However, increasing the dosage of anthracycline or Ara-c, or adding fludarabine, cladribine or etoposide into the classical ' $7+3$ ' framework produced a CR rate of $75 \%$, but the early mortality rate was increased (5-11).

Notably, the present study identified that the HCE scheme did not demonstrate cross-resistance with the IA scheme, which is concordant with previous studies $(29,30)$. Among the 10 patients that responded poorly in the HCE group, 8 were subsequently treated with the IA scheme and 7 cases achieved CR. Among the 26 patients that responded poorly in the IA group, 19 were then treated with the HCE scheme and 14 of these achieved CR. 

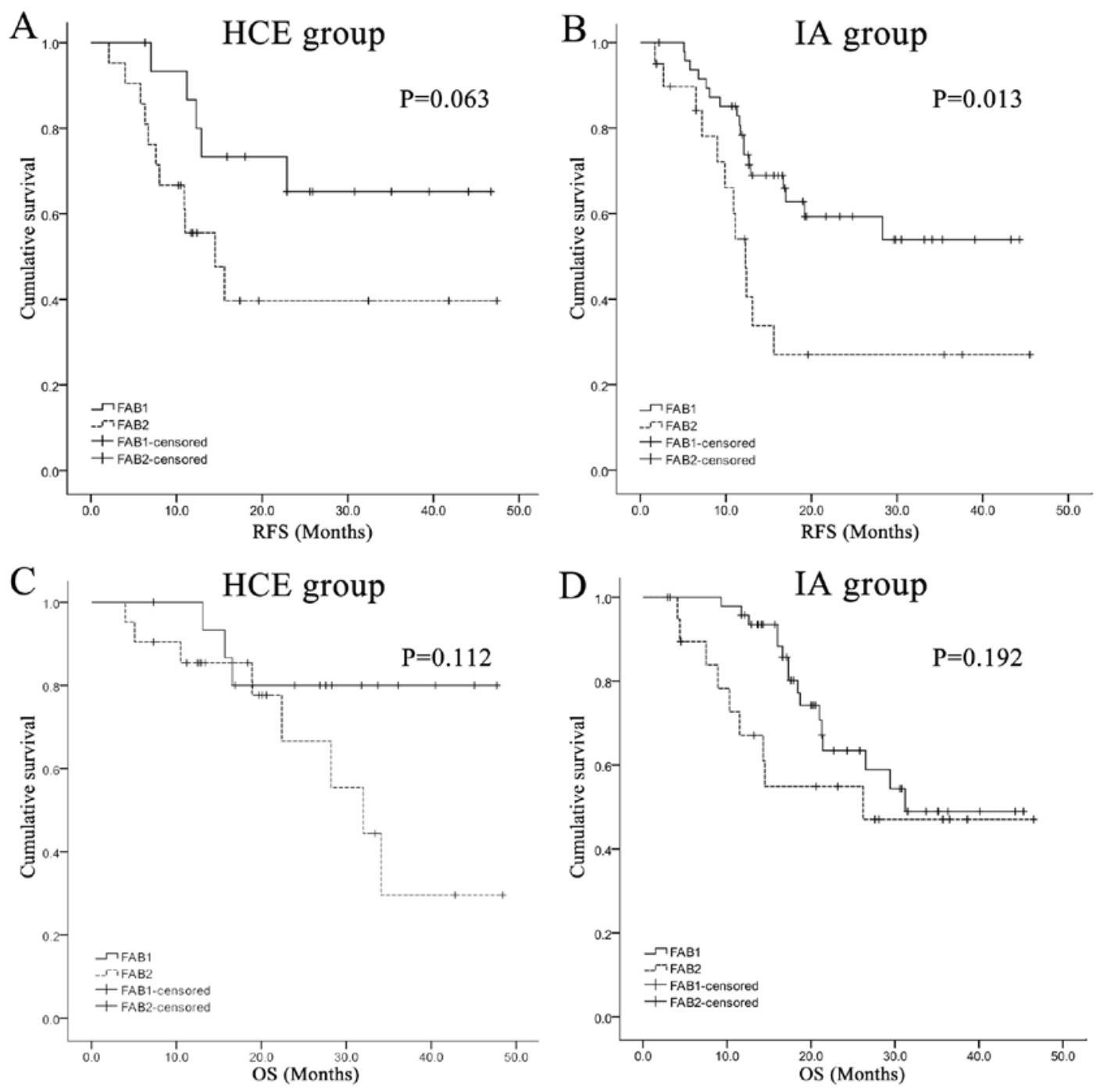

Figure 2. (A and B) RFS and (C and D) OS in patients with acute myeloid leukemia from FAB1 (M0-3) and FAB2 (M4/M5) subgroups in the HCE and IA treatment groups. FAB, French-American-British; RFS, relapse-free survival; OS, overall survival; HCE, homobarringtonie, cytosine arabinoside and etoposide; IA, idamycin and cytosine arabinocide.

When patients did not respond to HCE or IA induction therapy, they were administered the alternative treatment regimen and the resulting $\mathrm{CR}$ rate was $>70 \%$ suggesting that the underlying mechanisms of drug resistance in the two groups may not be associated. Therefore, HCE may be an alternative option for patients that respond poorly to IA induction therapy.

From the subgroup analysis, the CR rate of the patients in the HCE regimen group of $>50$ years was $91.7 \%$ (11/12), which was significantly improved compared with the $74.3 \% \mathrm{CR}$ rate of patients $<50$ years $(26 / 35)$. However, the CR rate of patients in the IA regimen group $>50$ years was $65.5 \%$, with similar values to those for HCE patients that were $<50$ years (CR, 75.4\%). The RFS and OS rates, which were similar in patients that were $<50$ years in the two groups, differed in the older patients between the HCE and IA treatment groups (RFS, 62.3 vs. 47.8\%; OS, 66.3 vs. 27.6\%). These results contrast the meta-analysis performed by Kantarjian et al (32), in which the CR rate was lower in the elderly compared with that of the overall population. However, previous Chinese studies $(32,36-40)$ have found that HBT may be administered at a rate of $4 \mathrm{mg} /$ day for 5 to 7 days or at the lower dose of
$1 \mathrm{mg} /$ day for 14 days for elderly (>60 years) patients with AML. This previous study hypothesized that the lower CR rate in elderly patients may be due to the reduced doses of HBT that were administered (32). However, the majority of previous studies are retrospective, non-randomized or small clinical trials $(32,36-40)$ and therefore, require further validation using a large cohort of patients in a randomized and controlled clinical trial.

The current study has demonstrated that cytogenetic and molecular abnormalities were able to affect AML induction therapy, RFS and OS, as well as being potential effective prognostic factors $(41,42)$. In low-risk patients, the CR rates of the HCE and IA groups were 84.6 and $95.8 \%$, respectively, and there was no significant difference between these groups. However, in the HCE group, high-risk patients experienced higher therapeutic efficacy with a CR rate of $<80 \%$, whereas the CR rate of the IA group was $60 \%$. This result was similar to that found for patients of $>50$ years, but the underlying mechanisms remain to be elucidated.

Regarding the adverse reactions from HBT treatment, previous studies have identified that the primary toxic effects 

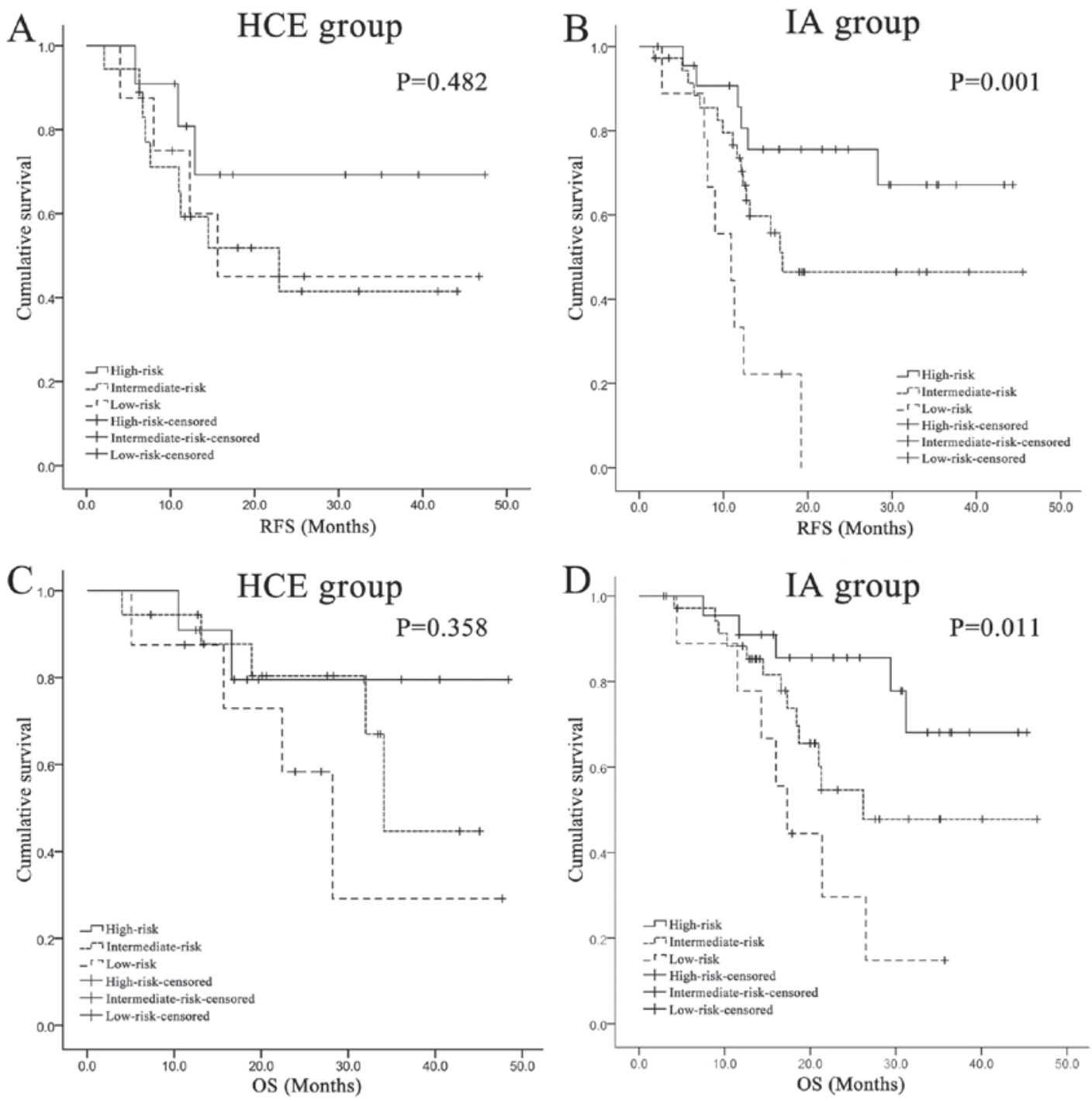

Figure 3. (A and B) RFS and (C and D) OS in patients with acute myeloid leukemia from each risk stratification group (low, intermediate and high risk), which is based on cytogenetic and molecular abnormalities of the patient samples. RFS, relapse-free survival; OS, overall survival; HCE, homobarringtonie, cytosine arabinoside and etoposide; IA, idamycin and cytosine arabinocide.

of HBT treatment are bone marrow inhibition, gastrointestinal reactions and cardiac toxicity, which frequently presents as supraventricular arrhythmias that respond to appropriate therapy $(13,29,30,32)$. In the treatment of CML, clinicians have administered long-term treatments with a duration of 14 to 28 days, and the typical level 3-4 adverse reaction that is detected is bone marrow inhibition without obvious non-hematological toxicity (18-20). During the treatment of elderly patients with long-term low dose chemotherapy, non-hematological toxicity from HBT has not been found (32,38-41). Previous studies have identified cases of grade 4 left bundle branch block during HBT therapy, or grade 2 QT interval prolonged (42), which was not associated with the blood concentration of HBT (43). In the current study, the non-hematological toxicity adverse reactions from HBT treatment were minimal and considered acceptable, and the typical level 3-4 adverse reaction that was detected was hematological toxicity. The duration of agranulocytosis and severe thrombocytopenia in the HBT treatment group was comparable with that of the IA regimen and demonstrated no severe non-hematological toxicity.
In conclusion, the HCE regimen may be an alternative treatment option for primary AML that has no cross-resistance with the current IA treatment regimen and demonstrates similar therapeutic efficacy and toxicity to the IA scheme, which is considered to be well-tolerated by patients. However, previous clinical studies and basic mechanistic studies have yet to fully investigate this topic. The cohort size in the present study was not sufficient to present unequivocal conclusions. Therefore, further multicenter prospective clinical trials with large numbers of patients are required in order to confirm the therapeutic efficacy and safety of HBT treatment for myeloid leukemia, to validate the efficacy and survival variation among age groups, subtypes and gene characteristics and to determine the optimal drug combinations and doses.

\section{Acknowledgements}

The present study was supported by the Science Technology Department of Zhejiang Province (grant no. 2016C33G2010095). 


\section{References}

1. Löwenberg B, Downing JR and Burnett A: Acute myeloid leukemia. N Engl J Med 341: 1051-1062, 1999.

2. NCCN Clinical Practice Guidelines in Oncology: Acute Myeloid Leukemia. National Comprehensive Cancer Network, version 2.2014. http://williams.medicine.wisc.edu/aml.Accessed December 30, 2015.

3. Stein EM: Molecularly targeted therapies for acute myeloid leukemia. Hematology Am Soc Hematol Educ Program 2015: 579-583, 2015.

4. Xue YP, Bian SG, Meng QX, Mi YC and Yang DG: Clinical observation of HAD regien in adult acute myeloid leukemia treatment. Chin J Hematol 16: 59-61, 1995.

5. Löwenberg B, Pabst T, Vellenga E, van Putten W, Schouten HC, Graux C, Ferrant A, Sonneveld P, Biemond BJ, Gratwohl A, et al: Cytarabine dose for acute myeloid leukemia. N Engl J Med 364: 1027-1036, 2011.

6. Löwenberg B: Sense and nonsense of high-dose cytarabine for acute myeloid leukemia. Blood 121: 26-28, 2013

7. Fernandez HF, Sun Z, Yao X, Litzow MR, Luger SM, Paietta EM, Racevskis J, Dewald GW, Ketterling RP, Bennett JM, et al: Anthracycline dose intensification in acute myeloid leukemia. N Engl J Med 361: 1249-1259, 2009.

8. Gardin C, Chevret S, Pautas C, Turlure P, Raffoux E, Thomas X, Quesnel B, de Revel T, de Botton S, Gachard N, et al: Superior long-term outcome with idarubicin compared with high-dose daunorubicin in patients with acute myeloid leukemia age 50 years and older. J Clin Oncol 31: 321-327, 2013.

9. Pautas C, Merabet F, Thomas X, Raffoux E, Gardin C, Corm S, Bourhis JH, Reman O, Turlure P, Contentin N, et al: Randomized study of intensified anthracycline doses for induction and recombinant interleukin-2 for maintenance in patients with acute myeloid leukemia age 50 to 70 years: Results of the ALFA-9801 study. J Clin Oncol 28: 808-814, 2010

10. Bishop JF, Matthews JP, Young GA, Bradstock K and Lowenthal RM: Intensified induction chemotherapy with high dose cytarabine and etoposide for acute myeloid leukemia: A review and updated results of the Australian Leukemia Study Group. Leuk Lymphoma 28: 315-327, 1998.

11. Holowiecki J, Grosicki S, Giebel S, Robak T, Kyrcz-Krzemien S, Kuliczkowski K, Skotnicki AB, Hellmann A, Sulek K, Dmoszynska A, et al: Cladribine, but not fludarabine, added to daunorubicin and cytarabine during induction prolongs survival of patients with acute myeloid leukemia: A multicenter, randomized phase III study. J Clin Oncol 30: 2441-2448, 2012.

12. Fresno M, Jimenéz A and Vázquez D: Inhibition of translation in eukaryotic systems by harringtonine. Eur J Biochem 72: 323-330, 1977.

13. Gurel G, Blaha G, Moore PB and Steitz TA: U2504 determines the species specificity of the A-site cleft antibiotics: The structures of tiamulin, homoharringtonine, and bruceantin bound to the ribosome. J Mol Biol 389: 146-156, 2009.

14. Baaske DM and Heinstein P: Cytotoxicity and cell cycle specificity of homoharringtonine. Antimicrob Agents Chemother 12: 298-300, 1977.

15. Zhou DC, Zittoun R and Marie JP: Homoharringtonine: An effective new natural product in cancer chemotherapy. Bull Cancer 82: 987-995, 1995.

16. Cortes J, Lipton JH, Rea D, Digumarti R, Chuah C, Nanda N, Benichou AC, Craig AR, Michallet M, Nicolini FE, et al: Phase 2 study of subcutaneous omacetaxine mepesuccinate after TKI failure in patients with chronic-phase CML with T315I mutation. Blood 120: 2573-2580, 2012.

17. Cortes J, Digumarti R, Parikh PM, Wetzler M, Lipton JH, Hochhaus A, Craig AR, Benichou AC, Nicolini FE, Kantarjian HM, et al: Phase 2 study of subcutaneous omacetaxine mepesuccinate for chronic-phase chronic myeloid leukemia patients resistant to or intolerant of tyrosine kinase inhibitors. Am J Hematol 88: 350-354, 2013.

18. Alvandi F, Kwitkowski VE, Ko CW, Rothmann MD, Ricci S, Saber H, Ghosh D, Brown J, Pfeiler E, Chikhale E, et al: U.S. Food and drug administration approval summary: Omacetaxine mepesuccinate as treatment for chronic myeloid leukemia. Oncologist 19: 94-99, 2014

19. Jin J, Jiang DZ, Mai WY, Meng HT, Qian WB, Tong HY, Huang J, Mao LP, Tong Y, Wang L, et al: Homoharringtonine in combination with cytarabine and aclarubicin resulted in high complete remission rate after the first induction therapy in patients with de novo acute myeloid leukemia. Leukemia 20: 1361-1367, 2006.
20. Jin J, Wang JX, Chen FF, Wu DP, Hu J, Zhou JF, Hu JD, Wang JM, Li JY, Huang XJ, et al: Homoharringtonine-based induction regimens for patients with de-novo acute myeloid leukaemia: A multicentre, open-label, randomised, controlled phase 3 trial. Lancet Oncol 14: 599-608, 2013.

21. Xiao Z, Xue H, Li R, Zhang L, Yu M and Hao Y: The prognostic signifi cance of leukemic cells clearance kinetics evaluation during the initial course of induction therapy with HAD (homoharringtonine, cytosine arabinoside, daunorubicin) in patients with de novo acute myeloid leukemia. Am J Hematol 83: 203-205, 2008.

22. Qin TJ, Xu ZF, Fang LW, Zhang HL, Zhang Y, Wang JZ, Pan LJ, $\mathrm{Hu}$ NB and Xiao ZJ: Clinical study on combination of homoharringtonine, ara-c and idarubicin induction for treatment of newly diagnosed acute myeloid leukemia patients. Zhongguo Shi Yan Xue Ye Xue Za Zhi 19: 1277-1282, 2011 (In Chinese).

23. Vardiman JW, Thiele J, Arber DA, Brunning RD, Borowitz MJ, Porwit A, Harris NL, Le Beau MM, Hellström-Lindberg E, Tefferi A, et al: The 2008 revision of the World Health Organization (WHO) classification of myeloid neoplasms and acute leukemia: rationale and important changes. Blood 114: 937-951, 2009.

24. Schreck RR and Disteche CM: Chromosome banding techniques. Curr Protoc Hum Genet Chapter 4: Unit4.2, 2001.

25. Bienz M, Ludwig M, Leibundgut EO, Mueller BU, Ratschiller D, Solenthaler M, Fey MF and Pabst T: Risk assessment in patients with acute myeloid leukemia and a normal karyotype. Clin Cancer Res 11: 1416-1424, 2005.

26. Bennett JM, Catovsky D, Daniel MT, Flandrin G, Galton DA, Gralnick HR and Sultan C: Proposals for the classification of the acute leukaemias. French-American-British (FAB) co-operative group. Br J Haematol 33: 451-458, 1976.

27. National Cancer Institute: Common Terminology Criteria for Adverse Events (CTCAE). National Cancer Institute, Division of Cancer Treatment and Diagnosis, version 3.0. https://ctep.cancer. gov/protocolDevelopment/electronic_applications/ctc.html. Accessed December 28, 2015.

28. Zheng BG, Luo XS, Zhou YH, Zheng ZY, Shen YP, Lin SY and $\mathrm{Hu} \mathrm{ZP}$ : The treatment of HA regimen in 34 patients with acute non-lymphocytic leukemia. Chin J Hematol 10: 405-406, 1989.

29. Fu YH and Liu YZ: 106 cases of acute myeloid leukemia treated with HA or DA regimen. Hu Nan Yi Xue 18: 390, 2001.

30. Bian SG, Hao YS and Wang ZC: Study of the treatment of adult acute non-lymphocytic leukemia. Chin J Hematol 14: 59-62, 1993.

31. Xiao Z, Xue H, Li R, Zhang L, Yu M and Hao Y: The prognostic significance of leukemic cells clearance kinetics evaluation during the initial course of induction therapy with HAD (homoharringtonine, cytosine arabinoside, daunorubicin) in patients with de novo acute myeloid leukemia. Am J Hematol 83: 203-205, 2008.

32. Kantarjian H, O'Brien S, Jabbour E, Barnes G, Pathak A and Cortes J: Effectiveness of homoharringtonine (omacetaxine mepesuccinate) for treatment of acute myeloid leukemia: A meta-analysis of Chinese studies. Clin Lymphoma Myeloma Leuk 15: 13-21, 2015.

33. Cai Z, Bao HY, Ludwig WD and Wuchter C: Expression and significance of apoptosis protein inhibitor survivin and $\mathrm{XIAP}$, in patients with myelodysplastic syndromes and in the cell line MUTZ-1. Zhonghua Xue Ye Xue Za Zhi 25: 26-30, 2004 (In Chinese).

34. Lu XY, Cao WK, Ye LL, Deng ZK, Zhang XH and Li YF: Time rhythm of homoharringtonine inducing K562 cell apoptosis and its mechanism. Zhongguo Shi Yan Xue Ye Xue Za Zhi 22: 712-716, 2014 (In Chinese).

35. Zhang T, Shen S, Zhu Z, Lu S, Yin X, Zheng J and Jin J: Homoharringtonine binds to and increases myosin-9 in myeloid leukaemia. Br J Pharmacol 173: 212-221, 2016.

36. Slovak ML, Kopecky KJ, Cassileth PA, Harrington DH, Theil KS, Mohamed A, Paietta E, Willman CL, Head DR, Rowe JM, et al: Karyotypic analysis predicts outcome of preremission and postremission therapy in adult acute myeloid leukemia: A Southwest Oncology Group/Eastern Cooperative Oncology Group Study. Blood 96: 4075-4083, 2000.

37. Schlenk RF, Döhner K, Krauter J, Fröhling S, Corbacioglu A, Bullinger L, Habdank M, Spath D, Morgan M, Benner A, et al: Mutations and treatment outcome in cytogenetically normal acute myeloid leukemia. N Engl J Med 358: 1909-1918, 2008.

38. Feldman E, Arlin Z, Ahmed T, Mittelman A, Puccio C, Chun H, Cook $\mathrm{P}$ and Baskind P: Homoharringtonine in combination with cytarabine for patients with acute myelogenous leukemia. Leukemia 6: 1189-1191, 1992. 
39. Wu L, Li X, Chang C, Xu F, He Q, Wu D, Zhang Z, Su J, Zhou L, Song L, et al: Efficacy and toxicity of decitabine versus CHG regimen (low-dose cytarabine, homoharringtonine and granulocyte colony-stimulating factor) in patients with higher risk myelodysplastic syndrome: a retrospective study. Leuk Lymphoma 57: 1367-1374, 2016.

40. Chen C, Xu W and Yang J: Low-dose homoharringtonine and cytarabine in combination with granulocyte colony-stimulating factor for elderly patients with de novo acute myeloid leukemia. Leuk Lymphoma 56: 141-146, 2015.

41. Hu X, Fu W, Wang L, Gao L, Lü S, Xi H, Qiu H, Chen L, Chen J, Ni X, et al: HAG regimen improves survival in adult patients with hypocellular acute myeloid leukemia. Oncotarget 7: 3623-3634, 2016.
42. Daver N, Vega-Ruiz A, Kantarjian HM, Estrov Z, Ferrajoli A, Kornblau S, Verstovsek S, Garcia-Manero G and Cortes JE: A phase II open-label study of the intravenous administration of homoharringtonine in the treatment of myelodysplastic syndrome. Eur J Cancer Care (Engl) 22: 605-611, 2013.

43. Nemunaitis J, Mita A, Stephenson J, Mita MM, Sarantopoulos J, Padmanabhan-Iyer S, Nanda N, Gleich L, Benichou AC and Craig A: Pharmacokinetic study of omacetaxine mepesuccinate administered subcutaneously to patients with advanced solid and hematologic tumors. Cancer Chemother Pharmacol 71: 35-41, 2013. 